\title{
Electrophysiologic Effects of Intravenous MS-551, a Novel Class III Antiarrhythmic Agent, on Human Atrium and Ventricle
}

\author{
Naoki NaITOH, MD, Koji TANEDA, MD, \\ Minoru Tagawa, MD, Hiroshi Furushima, MD, \\ Masayuki YAMAURA, MD, \\ and Yoshifusa Alzawa, MD
}

\section{SUMMARY}

The effects of intravenous MS-551, a new class III antiarrhythmic drug, on atrium and ventricle were evaluated in 6 patients with ventricular tachyarrhythmias ( 4 males and 2 females; mean age $45 \pm 21$ years) in an electrophysiologic study. Two patients had sustained ventricular tachycardia (VT) and 4 patients had ventricular fibrillation (VF). Electrophysiologic study was performed before and after the administration of MS-55 1 (loading infusion $0.3 \mathrm{mg} / \mathrm{kg}$ for $5 \mathrm{~min}+0.01 \mathrm{mg} / \mathrm{kg} / \mathrm{min}$ ).

The QT and QTc intervals were significantly prolonged by MS-551 from $359 \pm 52$ to $411 \pm 63 \mathrm{msec}(p=0.01)$ and from $410 \pm 36$ to $452 \pm 47$ $(p=0.0172)$, respectively. No effect was observed on the sinus cycle length, $\mathrm{QRS}$ duration, or $\mathrm{AH}$ and $\mathrm{HV}$ intervals in sinus rhythm.

The effective refractory periods of the right atrium (AERP) were significantly prolonged at paced cycle lengths of 600 (from $222 \pm 19$ to $250 \pm 23$ msec, $\mathrm{p}=0.0009$ ), 400 (from $207 \pm 15$ to $228 \pm 15, p<0.0001$ ) and 300 (from $193 \pm 10$ to $205 \pm 8 \mathrm{msec}, p=0.0127) \mathrm{msec}$. Similarly, the right ventricular ERP (VERP) were significantly prolonged at paced cycle lengths of 600 (from $240 \pm 23$ to $268 \pm 23 \mathrm{msec}, p<0.000 \mathrm{l}$ ), 400 (from $225 \pm 22$ to $250 \pm 24 \mathrm{msec}$, $p=0.0007$ ), and $300 \mathrm{msec}$ (from $213 \pm 14$ to $228 \pm 18 \mathrm{msec}, p=0.0071$ ). MS551 prolonged AERP and VERP in a "reverse" use-dependent manner without changing the conduction time in patients with ventricular tachyarrhythmias.

MS-551 prevented the induction of VT in 1 patient and VF in only 1 patient in this electrophysiologic study. Further evaluation of the therapeutic potential of MS-551 using higher dosages is necessary. (Jpn Heart J 1998; 39: 297-305)

Key words: MS-551, Reverse use dependency, Class III antiarrhythmic agent, Refractory period

\footnotetext{
From the First Department of Internal Medicine, Niigata University School of Medicine, Niigata, Japan. Address for correspondence: Naoki Naitoh, MD, First Department of Internal Medicine, Niigata University School of Medicine, 1-754 Asahimachi-Dori, Niigata 951, Japan.

Received for publication January 13, 1998.

Accepted February 4, 1998.
} 
T efforts to control cardiac arrhythmias by the use of antiarrhythmic drugs, either slowing the conduction or lengthening the repolarization of myocardium, or both have been widely attempted. ${ }^{1-3)}$ Class III antiarrhythmic drugs ${ }^{4)}$ have the ability to prolong the action potential duration (APD) and refractory period, mainly by blocking potassium currents. ${ }^{1-4)}$ Among currently available class III antiarrhythmic drugs, some exhibit a nonspecific potassium channel blocking effect, whereas E-4031 and dofetilide selectively block the potassium current. ${ }^{5)}$ Many recent studies have examined the electrophysiologic effects of selective class III agents [e.g., sematilide, ${ }^{6-8)}$ dofetilide, ${ }^{9-11)} \mathrm{E}-403 \mathrm{I}^{12-15)}$ and $\mathrm{d}-$ sotalol $\left.{ }^{16}\right]$ in animals or humans.

The electrophysiologic effects of a new class III antiarrhythmic drug such as MS-551 in patients with ventricular tachyarrhythmias are not fully known. The present study examined the electrophysiologic effects of MS-551 on the human atrium and ventricle by measuring the conduction time and effective refractory period.

\section{MeTHODS}

Patients: The study group consisted of 6 patients with ventricular tachyarrhythmia. There were 4 males and 2 females, with a mean age of $45 \pm 12$ years (range 16 to 64 ). The ventricular tachyarrhythmia was related to remote myocardial infarction, idiopathic dilated cardiomyopathy, arrhythmogenic right ventricular dysplasia, post-operative status of congenital heart disease, postmyocarditis, and no evidence of structural heart disease, in one patient each. The indications for electrophysiologic study were symptomatic sustained ventricular tachycardia (VT) in 2 patients and polymorphic ventricular tachycardia

Table I. Electrophysiologic Data during Sinus Rhythm

\begin{tabular}{|c|c|c|c|c|c|c|c|c|c|c|c|c|c|c|}
\hline \multirow{2}{*}{ No. } & \multirow{2}{*}{\multicolumn{2}{|c|}{ Year/Gender SHD }} & \multicolumn{2}{|c|}{ SCL(ms) } & \multicolumn{2}{|c|}{$\mathrm{AH}(\mathrm{ms})$} & \multicolumn{2}{|c|}{$\mathrm{HV}(\mathrm{ms})$} & \multicolumn{2}{|c|}{$\mathrm{QRS}(\mathrm{ms})$} & \multicolumn{2}{|c|}{$\mathrm{QT}(\mathrm{ms})$} & \multicolumn{2}{|c|}{$\mathrm{QTc}(\mathrm{ms})$} \\
\hline & & & C & $\mathbf{M}$ & C & $\mathbf{M}$ & C & $\mathbf{M}$ & C & $\mathbf{M}$ & C & $\mathbf{M}$ & C & $\mathbf{M}$ \\
\hline $1^{*}$ & $19 \mathrm{M}$ & post-ope & 670 & 700 & - & - & - & - & 120 & 125 & 345 & 370 & 421 & 440 \\
\hline $2^{*}$ & $50 \mathrm{M}$ & ARVD & 640 & 910 & - & - & - & - & 90 & 90 & 320 & 420 & 400 & 440 \\
\hline 3 & $64 \mathrm{~F}$ & DCM & 860 & 885 & 100 & 100 & 50 & 50 & 155 & 155 & 430 & 490 & 462 & 521 \\
\hline 4 & $16 \mathrm{~F}$ & Idio & 1030 & 920 & 120 & 110 & 40 & 40 & 150 & 150 & 420 & 475 & 414 & 495 \\
\hline 5 & $60 \mathrm{M}$ & Myocarditis & 600 & 640 & 100 & 100 & 40 & 40 & 90 & 90 & 320 & 330 & 413 & 413 \\
\hline 6 & $58 \mathrm{M}$ & MI & 830 & 895 & 110 & 110 & 65 & 65 & 90 & 90 & 320 & 380 & 352 & 400 \\
\hline Mean & 45 & & 772 & 825 & 108 & 105 & 49 & 49 & 116 & 117 & 359 & 411 & 410 & 452 \\
\hline$\pm \mathrm{SD}$ & $2]$ & & 164 & 122 & 10 & 6 & 12 & 12 & 31 & 31 & 52 & 63 & 36 & 47 \\
\hline \multicolumn{3}{|c|}{$\begin{array}{l}p \text {-value } \\
\% \text { Change }\end{array}$} & \multicolumn{2}{|c|}{ NS } & \multicolumn{2}{|c|}{ NS } & \multicolumn{2}{|c|}{ NS } & \multicolumn{2}{|c|}{ NS } & \multicolumn{2}{|c|}{$\begin{array}{l}0.0100 \\
+14.4 \%\end{array}$} & \multicolumn{2}{|c|}{$\begin{array}{c}0.0172 \\
+10.0 \%\end{array}$} \\
\hline
\end{tabular}

SHD = structural heart disease; DCM = dilated cardiomyopathy; ARVD = arrhythmogenic right ventricular dysplasia; $\mathrm{MI}=$ myocardial infarction; $\mathrm{C}=$ control; $\mathrm{M}=$ after $\mathrm{MS}-55 \mathrm{l}$ administration; $\mathrm{SCL}=$ sinus cycle length; *Patient with sustained ventricular tachycardia. 
or ventricular fibrillation (VF) in 4 patients (Table I).

Electrophysiologic study: After informed consent was obtained from each patient, the electrophysiologic study was performed as described previously. ${ }^{17)}$ In brief, the protocol of the induction of ventricular tachyarrhythmia consisted of single and double (triple when necessary) extrastimuli at two basic cycle lengths, 600 and $400 \mathrm{~ms}$, and the incremental pacing at cycle lengths from 667 to $286 \mathrm{~ms}$ for 5-15 sec at two sites of the right ventricle and a single site of the left ventricle. Stimulation with rectangular pulses of $2 \mathrm{~ms}$ duration at twice diastolic threshold was used.

After we obtained all appropriate baseline electrophysiologic data, we infused a loading dose of MS-551 $(0.3 \mathrm{mg} / \mathrm{kg})$ for $5 \mathrm{~min}$ and then a maintenance dose of $0.01 \mathrm{mg} / \mathrm{kg} / \mathrm{min}$. The maintenance infusion was continued throughout the electrophysiologic measurements which were started $5 \mathrm{~min}$ after the end of the loading infusion.

Definitions: Sustaincd VT was defined as VT lasting for 30 seconds or longer, or having to be terminated prior to 30 seconds because of hemodynamic deterioration. Non-sustained VT was defined as VT lasting for 6 beats or more and self terminating within 30 seconds. Ventricular fibrillation (VF) was defined as a tachycardia with irregular cycle lengths and discrete QRS complexes on the surface electrocardiogram.

The atrial effective refractory period (AERP) at the high right atrium and the ventricular ERP (VERP) at the right ventricular apex were measured as the longest coupling interval which failed to capture the myocardium at three paced cycle lengths of 600,400 , and $300 \mathrm{msec}$.

The QRS duration was measured in lead $V_{1}$ during sinus rhythm and pacing at the right ventricular apex (P-QRS) at three paced cycle lengths of 600 , 400 , and $300 \mathrm{msec}$ and used as an index of global ventricular conduction time. The pacing spike was used as the onset of the QRS duration.

The QT interval was measured from the onset of the QRS to the end of the $T$ wave measured in lead $V_{1}$ during sinus rhythm. The QT interval was corrected for heart rate using Bazett's formula.

Statistical analysis: The electrophysiologic parameter data are presented as mean \pm standard deviation (SD). Differences in each variable between before and after MS-55l administration were analyzed using a paired $t$-test. The changes in the QRS duration, AERP and VERP before and after MS-551 administration were compared at three paced cycle lengths using repeated-measures ANOVA. A value of $p<0.05$ was considered significant. 


\section{Results}

Effects of MS-551 on electrophysiologic parameters in sinus rhythm: The electrophysiologic effects of MS-551 in sinus rhythm are shown in Table I. There were no significant changes in sinus cycle length (SCL) or QRS duration. The QT and QTc intervals were significantly prolonged by MS-551 administration from $359 \pm 52$ to $411 \pm 63 \mathrm{msec}(p=0.01)$ and $410 \pm 36$ to $452 \pm 47 \mathrm{msec}$ $(p=0.0172)$, respectively.

Effects of MS-551 on atrium: The electrophysiologic effects of MS-551 in atrial pacing are summarized in Table II. There were no significant changes in sinus cycle length, $\mathrm{AH}$ interval, or $\mathrm{HV}$ interval after the administration of MS551. MS-551 significantly prolonged the AERP at paced cycle lengths of 600

Table II. Electrophysiologic Data in Atrial Pacing

\begin{tabular}{|c|c|c|c|c|c|c|}
\hline \multirow{3}{*}{ No. } & & & \multicolumn{2}{|c|}{$\operatorname{AERP}$ (msec) } & & \\
\hline & \multicolumn{2}{|c|}{ BCL 600} & \multicolumn{2}{|c|}{ BCL400 } & \multicolumn{2}{|c|}{ BCL300 } \\
\hline & $\mathrm{C}$ & $\mathbf{M}$ & $\mathrm{C}$ & M & C & $\mathbf{M}$ \\
\hline 1 & 200 & 230 & 190 & 210 & 180 & 200 \\
\hline 2 & 210 & 230 & 200 & 220 & 190 & 200 \\
\hline 3 & 250 & 290 & 230 & 250 & 210 & 220 \\
\hline 4 & 220 & 240 & 200 & 220 & 190 & 200 \\
\hline 5 & 210 & 250 & 200 & 230 & 190 & 210 \\
\hline 6 & 240 & 260 & 220 & 240 & 200 & 200 \\
\hline Mean & 222 & 250 & 207 & 228 & 193 & 205 \\
\hline$\pm \mathrm{SD}$ & 19 & 23 & 15 & 15 & 10 & 8 \\
\hline$p$-value & \multicolumn{2}{|c|}{0.0009} & \multicolumn{2}{|c|}{$<0.0001$} & \multicolumn{2}{|c|}{0.0127} \\
\hline
\end{tabular}

AERP = atrial effective refractory period; $\mathrm{BCL}=$ basic cycle length. Other abbreviations are the same as in Table I.

Table III. Electrophysiologic Data in Ventricular Pacing

\begin{tabular}{|c|c|c|c|c|c|c|c|c|c|c|c|c|}
\hline \multirow{3}{*}{ No. } & \multicolumn{6}{|c|}{ P-QRS (msec) } & \multicolumn{6}{|c|}{ VERP (msec) } \\
\hline & \multicolumn{2}{|c|}{ BCL 600} & \multicolumn{2}{|c|}{ BCL 400} & \multicolumn{2}{|c|}{ BCL 300} & \multicolumn{2}{|c|}{ BCL 600} & \multicolumn{2}{|c|}{ BCL 400} & \multicolumn{2}{|c|}{ BCL 300} \\
\hline & C & $\mathbf{M}$ & $\mathrm{C}$ & $M$ & $\mathrm{C}$ & $M$ & $\mathrm{C}$ & M & C & $\mathbf{M}$ & $\mathrm{C}$ & $\mathbf{M}$ \\
\hline 1 & 165 & 165 & 150 & 170 & 155 & 160 & 240 & 260 & 210 & 220 & 200 & 210 \\
\hline 2 & 170 & 170 & 160 & 160 & 165 & 165 & 210 & 240 & 200 & 230 & 200 & 220 \\
\hline 3 & 170 & 170 & 150 & 150 & 160 & 160 & 240 & 270 & 230 & 260 & 210 & 230 \\
\hline 4 & 175 & 175 & 155 & 155 & 165 & 165 & 220 & 250 & 210 & 240 & 210 & 210 \\
\hline 5 & 220 & 220 & 210 & 200 & 210 & 210 & 270 & 300 & 250 & 280 & 230 & 250 \\
\hline 6 & 205 & 200 & 190 & 180 & 190 & 190 & 260 & 290 & 250 & 270 & 230 & 250 \\
\hline Mean & 184 & 183 & 169 & 169 & 175 & 176 & 240 & 268 & 225 & 250 & 213 & 228 \\
\hline$\pm \mathrm{SD}$ & 23 & 22 & 25 & 19 & 21 & 20 & 23 & 23 & 22 & 24 & 14 & 18 \\
\hline$p$-value & \multicolumn{2}{|c|}{ NS } & \multicolumn{2}{|c|}{ NS } & \multicolumn{2}{|c|}{ NS } & \multicolumn{2}{|c|}{$<0.0001$} & \multicolumn{2}{|c|}{0.0007} & \multicolumn{2}{|c|}{0.0071} \\
\hline
\end{tabular}

$P-Q R S=$ paced $Q R S$ duration in ventricular stimulation; VERP = ventricular ERP. Other abbreviations are the same as in Tables I and II. 


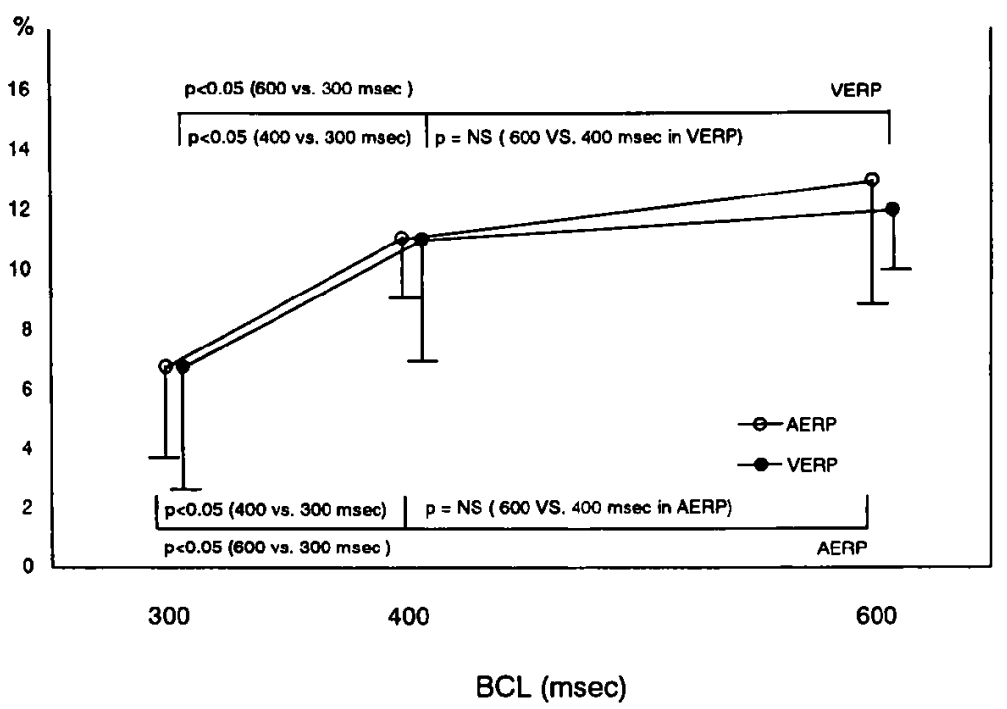

Figure. The percentage of prolongation of the MS-55l-induced atrial and ventricular effective refractory period (AERP and VERP) at three different basic cycle lengths. The percentage of prolongation of the ERP at each of three paced cycle lengths was similar in atrium and ventricle. There were reverse use-dependent effects on AERP and VERP.

(from $222 \pm 19$ to $250 \pm 23 \mathrm{msec}, p=0.0009$ ), 400 (from $207 \pm 15$ to $228 \pm 15$ $\mathrm{msec}, p<0.0001$ ), and $300 \mathrm{msec}$ (from $193 \pm 10$ to $205 \pm 8 \mathrm{msec}, p=0.0127$ ). The percentile of the MS-551-induced AERP prolongation (\% change) at paced cycle lengths of $600(12.8 \pm 4.4 \%)$ and $400(10.7 \pm 2.3 \%)$ msec were significantly longer than that at $300 \mathrm{msec}(7.0 \pm 3.1 \% ; p<0.05)$.

Effects of MS-551 on ventricle: As shown in Table III, MS-551 did not prolong the paced QRS duration at three paced cycle lengths. In contrast to the paced QRS duration, MS-551 significantly prolonged the VERP at paced cycle lengths of 600 (from $240 \pm 23$ to $268 \pm 23 \mathrm{msec}, p<0.000 \mathrm{l}$ ), 400 (from $225 \pm 22$ to $250 \pm 24 \mathrm{msec}, p=0.0007$ ), and $300 \mathrm{msec}$ (from $213 \pm 14$ to $228 \pm 18 \mathrm{msec}$, $p=0.0071)$. The $\%$ change of MS-551 of the VERP at paced cycle lengths of 600 $(12.0 \pm 2.3 \%)$ and $400(11.2 \pm 3.9 \%)$ msec were significantly longer than that at $300(7.2 \pm 4.0 \%) \operatorname{msec}(p<0.05)$.

Use-dependent effect on atrial and ventricular refractoriness: As shown in the Figure, the \% changes in ERP were similar in atrium and ventricle at paced cycle lengths of 600 (12.8 $\pm 4.4 \%$ in atrium vs. $12.0 \pm 2.3 \%$ in ventricle, $p=\mathrm{NS})$, $400(10.7 \pm 2.3 \%$ in atrium vs. $11.2 \pm 3.9 \%$ in ventricle, $p=\mathrm{NS})$, and $300 \mathrm{msec}$ $(7.0 \pm 3.1 \%$ in atrium vs. $7.2 \pm 4.0 \%$ in ventricle, $p=\mathrm{NS})$.

Effects of ventricular tachyarrhythmias inducibility: In the baseline electrophysiologic study, ventricular tachyarrhythmia was induced by double 
$\left(\mathrm{S}_{2} \mathrm{~S}_{3}\right)$ premature stimuli in all patients. MS-551 completely suppressed the induction of V'T and VF in one patient each (patients 2 and 6).

The administration of MS-551 could not prevent the induction of VT in one (patient l) of 2 patients and VF in three (patients 3,4 and 5) of 4 patients. The cycle length of VT in patient 1 was prolonged slightly from 265 to $280 \mathrm{msec}$ (5.7\%) by the administration of MS-551 by double premature stimuli, similar to the baseline induction mode. In patient 3 , in whom VF was inducible by double premature stimuli in the baseline study, VF was induced by triple premature stimuli after the administration of MS-551. The induction mode in the remaining two patients (patients 4 and 5) after MS-551 administration were similar to the baseline study.

\section{Discussion}

A close correlation between the APD and the ERP has been shown in animals and humans. ${ }^{18-20)}$ Prolongation of the refractory period can be obtained by the inhibition of outward currents, increasing inward currents, or delaying the recovery of sodium channels during phase 3 of the action potential.,21) In the present study, MS-551, a novel class III antiarrhythmic drug, ${ }^{4)}$ significantly prolonged the ERP of the human atrium and ventricle, although it did not alter the ventricular conduction time as measured by the paced QRS duration at three paced cycle lengths and HV interval. In addition, MS-551 did not change the sinus rate. Such effects of MS-551 indicate that this drug possesses pure class III antiarrhythmic properties without the inhibition of $\mathrm{Na}$ current and $\boldsymbol{\beta}$ adrenoreceptor.

Moreover, the \% changes in ERP at three paced cycle lengths were similar in atrium and ventricle, as shown in the Figure. These effects of MS-551 on atrial and ventricular ERP in humans are similar to those of E-4031, a pure class III antiarrhythmic agent, as reported by Fujiki et al. ${ }^{15)}$

Hondeghem and Snyders pointed out the opposite use-dependent effects of class I antiarrhythmic drugs on the maximum rate of depolarization and of class III antiarrhythmic drugs on the prolongation of repolarization in myocardium. ${ }^{22}$ The degree of the lengthening of the APD by class III antiarrhythmic drugs decreases at high frequency. ${ }^{6-11,13,14,22,23)}$ The smaller action of class III antiarrhythmic drug-induced APD prolongation at high frequency has been called reverse use-dependency. ${ }^{22)}$

Fujiki and colleagues ${ }^{15)}$ observed that the effects of E-4031 on AERP were similar between basic cycle lengths of 600 and $400 \mathrm{msec}$ (14.6 vs. $13.6 \%$, respectively). Although the effects of MS-551 on the \% change of AERP and VERP between 600 and 400 msec were not significantly different in the present study 
( 12.8 vs. $10.7 \%$ in atrium, 12.0 vs. $11.2 \%$ in ventricle), the effects at basic cycle length of $300 \mathrm{msec}$ were lesser than those at basic cycle lengths of 600 and 400 msec, as shown in the Figure ( $p<0.05$ for both the atrium and ventricle). This result shows that MS-551 shows reverse use-dependency, as do other selective class III agents ${ }^{6-11,13,14,22-24)}$ in both the atrial and ventricular ERP.

In one patient, the same VT morphology as that shown in the baseline study was induced, but the cycle length of VT was prolonged only slightly (6\%) after the administration of MS-551.

Although the clinical implications of a reverse use-dependent effect on the refractoriness of several class III drugs are insufficiently known, these drugs may be less efficacious for the prevention of ventricular tachyarrhythmia and the slowing of the cycle length of ventricular tachyarrhythmia. ${ }^{5)}$ In the present study, we did not evaluate the effects of MS-551 on AERP and VERP at higher dosages. The therapeutic potential of higher dosages of MS-551 should be evaluated further.

Limitations: The present study had several following limitations. (1) Ventricular pacing was limited to a relatively narrow range of paced cycle lengths (300 to $600 \mathrm{msec}$ ) because of interference by sinus rhythm at longer cycle lengths and hemodynamic instability at shorter cycle lengths.

(2) We measured the ventricular conduction time and the ERP at the right ventricular apex, but the response to MS-551 may be different in the substrates of ventricular tachyarrhythmias. It is possible that such diseased and partially depolarized tissues might respond to MS-551 in a different manner.

(3) We tested only a narrow dose range of MS-551 and used a continuous drug infusion. Our observations may only apply to this dose of MS-551.

Conclusions: The results of this study have demonstrated that MS-551 was a class III agent that manifested a reverse use-dependent effect on atrial and ventricular ERP without sodium channel and $\beta$-blocking activity. We could not confirm the clinical usefulness of MS-551 in patients with ventricular tachyarrhythmias because of the small number of patients. The therapeutic potential of MS-55 I should be evaluated further.

\section{ReFERENCES}

1. Singh $\mathbf{N}$, Courtney $\mathbf{K}$. On the classification of antiarrhythmic mechanisms: experimental and clinical correlations. In: Zipes DP, Jalife J, editors. Cardiac Electrophysiology: From the Cell to Bedside. Philadelphia, Pa: WB Saunders Co; 1990: 882-97.

2. Singh BAN, Vaughan Williams EM. A third class of antiarrhythmic actions: effects on atrial and ventricular intracellular potentials, and other pharmacologic actions on cardiac muscle, of MJ1999 and AH3474. Br J Pharmacol 1970; 29: 675-87.

3. Singh BN, Nademanee K. Control of cardiac arrhythmias by selective lengthening of repolarization: theoretic considerations and clinical observations. Am Heart J 1985; 109: 421-30. 
4. Vaughan Williams EM. A classification of antiarrhythmic actions reassessed after a decade of new drugs. J Clin Pharmacol 1984; 24: 129-47.

5. Colatsky JJ, Follmer CH, Starmer CF. Channel specificity in antiarrhythmic drug action: mechanism of potassium channel block and its role in suppressing and aggravating cardiac arrhythmias. Circulation 1990; 82: 2235-42.

6. Sager TP, Nademanee K, Antimisiaris M, et al. Antiarrhythmic effects of selective prolongation of refractoriness: electrophysiologic actions of sematilide HCL in humans. Circulation 1993; 88: 1072-82.

7. Sager PT, Follmer C, Uppal P, Pruitt C, Godfrey R. The effects of $\boldsymbol{\beta}$-adrenergic stimulation on the frequency-dependent electrophysiologic actions of amiodarone and sematilide in humans. Circulation 1994; 90: 1811-9.

8. Argentieri TM, Carroll MS, Sullivan ME. Cellular electrophysiologic effects of the class III antiarrhythmic agents sematilide and clofilium on rabbit atrial tissue. J Cardiovasc Pharmacol 1991; 18 : 167-74.

9. Tande PM, Bjornstad H, Yang T, Refsum H. Rate-dependent class III antiarrhythmic action, negative chronotrophy, and positive inotrophy of a novel Ik blocking drug, UK-68, 798: potent in guinea pig but no effect in rat myocardium. J Cardiovasc Pharmacol 1990; 16: 401-10.

10. Jurkiewics NK, Sanguinetti MAC. Rate-dependent prolongation of cardiac action potentials by a methanesulfonanilide class III antiarrhythmic agent: specific block of rapidly activating delayed rectifier $\mathrm{K}^{+}$current by dofetilide. Circ Res 1993; 72: 75-83.

11. Sedgwick ML, Rasmussen HS, Cobbe SM. Effects of the class III antiarrhythmic drug dofetilide on ventricular monophasic action potential duration and QT interval dispersion in stable angina pectoris. Am J Cardiol 1992; 70: 1432-7.

12. Katoh H, Ogawa S, Furuno I, Yoh S, Saeki K, Nakamura Y. Electrophysiologic effects of E-4031, a class III antiarrhythmic agent, on reentrant ventricular arrhythmias in a canine 7-day-old myocardial infarction model. J Pharmacol Exp Ther 1990; 253: 1077-82.

13. Sanguinetti MC, Jurkiewicz NK, Scott A, Siegl PKS. Isoproterenol antagonizes prolongation of refractory period by the class III antiarrhythmic agent E-4031 in guinea pig myocytes: mechanism of action. Circ Res 1991; 68: 77-84.

14. Buskins SP, Serik CM, Wallace AA, et al. Effects of new and potent methanesulfonilide class III antiarrhythmic agents on myocardial refractoriness and contractility in isolated cardiac muscle. J Cardiovasc Pharmacol 1991; 18: 406-14.

15. Fujiki A, Tani M, Mizumaki K, Shimono M, Inoue H. Electrophysiologic effects of intravenous $\mathbf{E}$ 4031, a novel class III antiarrhythmic agent, in patients with supraventricular tachyarrhythmias. J Cardiovasc Pharmacol 1994; 23: 374-8.

16. Katoh R, Ikeda N, Yabek SM, Kannan R, Singh BN. Electrophysiologic effects of the levo- and dextrorotatory isomers of sotalol in isolated cardiac muscle and their in vivo pharmacokinetics. $\mathrm{J}$ Am Coll Cardiol 1986; 7: 116-25.

17. Aizawa $\mathbf{Y}$, Niwano $\mathrm{S}$, Chinushi $\mathbf{M}$, et al. Incidence and mechanism of interruption of reentrant ventricular tachycardia with rapid ventricular pacing. Circulation 1992; 85: 589-95.

18. Lee RJ, Leim B, Cohen TJ, Franz MR. Relation between repolarization and refractoriness in the human ventricle: cycle length dependence and effect of procainamide. J Am Coll Cardiol 1992; 19 : 614-8.

19. Nattel S, Zeng F-D. Frequency-dependent effects of antiarrhythmic drugs on action potential duration and refractoriness of canine cardiac Purkinje fibers. J Pharmacol Exp Ther 1984; 229: 283-91.

20. Franz MR, Swerdlow CD, Leim BL, Schaefer J. Cycle-length dependence of human action potential duration in vivo: effects of single extrastimuli, sudden sustained rate acceleration and deceleration, and different steady-state frequencies. J Clin Invest 1988; 82: 972-9.

21. Hondeghem LM, Katzung BG. Time- and voltage-dependent interactions of antiarrhythmic drugs with cardiac sodium channels. Biochim Biophys Acta 1977; 472: 373-98.

22. Hondeghem LAM, Snyders DJ. Class III antiarrhythmic agents have a lot of potential but a long way to go: reduced effectiveness and dangers of reverse use dependence. Circulation 1990; 81: 686-90.

23. Scmitt C, Brachmann J, Karch M, et al. Reverse use-dependent effects of sotalol demonstrated by recording monophasic action potentials of the right ventricle. Am J Cardiol 1991; 68: 1183-7. 
24. Okada Y, Ogawa S, Sadanaga T, Mitamura H. Assessment of reverse use-dependent blocking actions of class III antiarrhythmic drugs by 24-hour Holter electrocardiography. J Am Coll Cardiol 1996; 27 : 84-9. 